\title{
Response to the article titled, Erector spinae plane block for back surgery
}

\author{
Hadi Ufuk Yorukoglu' ${ }^{1}$. $\cdot$ Can Aksu ${ }^{1} \cdot$ Dilek İçli $^{1}$
}

Received: 15 November 2021 / Accepted: 18 November 2021 / Published online: 23 November 2021

(c) The Author(s) under exclusive licence to Japanese Society of Anesthesiologists 2021

\section{To the Editor:}

We thank Dr. Satomoto and Dr. Adachi for their interest [1] in our study [2]. We agree with Dr. Satomoto that erector spinae plane block (ESPB) can be performed unilaterally considering the surgical technique. In recent years, several microdiscectomy techniques have been described for lumbar disc herniations with similar outcomes [3]. In our clinic, open microdiscectomies are performed with a midline incision. Therefore, ESPB was applied bilaterally. We think it could be possible to apply unilateral ESPB in other minimally invasive techniques to perform a paramedian incision.

Moreover, Dr. Satomoto offered to increase the local anesthetic dose without the local anesthetic toxicity by performing ESPB unilaterally to extend the analgesic area. As we agree with this statement, is it necessary to extend the analgesic area for minimal invasive techniques? Higher volumes of local anesthetic are needed to cover one vertebral level for the lumbar region, and injecting high amounts of local anesthetic in lumbar areas may result in motor weakness which may complicate the postoperative neurologic assessment [4].

The mechanism of lumbar ESPB is still not clearly understood, and further studies are needed to determine the volume and concentrations of local anesthetics for each indication.

Funding None.

\section{Declarations}

Conflict of interest None.

\section{References}

1. Satomoto M, Adachi YU. Erector spinae plane block for back surgery. J Anesth. 2021. https://doi.org/10.1007/s00540-021-03001-y (Epub ahead of print).

2. Yörükoğlu HU, İçli D, Aksu C, Cesur S, Kuş A, Gürkan Y. Erector spinae block for postoperative pain management in lumbar disc hernia repair. J Anesth. 2021;35:420-5.

3. Ruan W, Feng F, Liu Z, Xie J, Cai L, Ping A. Comparison of percutaneous endoscopic lumbar discectomy versus open lumbar microdiscectomy for lumbar disc herniation: a meta-analysis. Int J Surg. 2016;31:86-92.

4. De Cassai A, Andreatta G, Bonvicini D, Boscolo A, Munari M, Navalesi P. Injectate spread in ESP block: a review of anatomical investigations. J Clin Anesth. 2020;61:1669.

Publisher's Note Springer Nature remains neutral with regard to jurisdictional claims in published maps and institutional affiliations.

This reply refers to the comment available online at https://doi.org/ 10.1007/s00540-021-03001-y.

Hadi Ufuk Yorukoglu

ufukyorukoglu@gmail.com

1 Department of Anesthesiology and Reanimation, Kocaeli

University, Kocaeli, Turkey 